\title{
EFFECTS OF GOLD MINING ON THE GENERAL POPULATION
}

\section{Amitha Hegde., Ankit Varun*., Momeka K and Vaisakh Vasudevan}

\author{
Department of Pedodontics, A.B. Shetty Memorial Institute of Dental Sciences, \\ NITTE University, Mangalore
}

DOI: http://dx.doi.org/10.24327/ijrsr.2017.0803.0115

\section{ARTICLE INFO}

\section{Article History:}

Received $17^{\text {th }}$ December, 2016

Received in revised form $21^{\text {st }}$

January, 2017

Accepted $05^{\text {th }}$ February, 2017

Published online $28^{\text {th }}$ March, 2017

\section{Key Words:}

Gold mining, Mercury, Arsenic, pigmentation, human health, Hutti village

\begin{abstract}
Hutti, one of the three functioning gold mines in India, is located in Raichur District of Karnataka. Mercury and arsenic, being active constituents of the Gold mining industry are known toxicants that are hazardous to humans, wildlife and domestic animals and may accumulate in the environment causing serious damage to ecosystems and human health. Hence a questionnaire based survey was conducted amongst the local population of the Hatti village. Most of the people who participated in the survey were aware of the ill effects of mining. In growing age these signs and symptoms are more pronounced than elders. Some of the most common health problems noticed were dark brown pigmentation of the skin (47\%), loose stool, breathing difficulties and fatigue. Female population reported 3\% abortions and miscarriages. The poor accessibility and unavailability of health care centers was the main reason for the increased incidence of health issues.
\end{abstract}

Copyright (C) Amitha Hegde et al, 2017, this is an open-access article distributed under the terms of the Creative Commons Attribution License, which permits unrestricted use, distribution and reproduction in any medium, provided the original work is properly cited.

\section{INTRODUCTION}

The local demand for gold in India has always been ona rise. According to national survey data there are only three functioning gold mines in India namely Hirabuddini mines in Jharkhand, and Hatti, Uti gold minesinKarnataka. ${ }^{1}$

The village of Hutti is located in Raichur District in the Indian state of Karnataka. This mine is probably one of the most ancient metal mines in the world. There was an extensive increase in gold mining in the area between 1890 and 1920. The industry closed down in 1920 due to technical difficulties and lack of funds. After the end of the second world war, the production started in September 1948, at the rate of 130 tonns of ore per day. By 1972 this rate had progressively increased to 600 tonnes of ore per day. ${ }^{2}$ The Company was originally formed in 1947 as the Hyderabad Gold mines Company Ltd., with the Hyderabad State Government holding a majority of the shares. With the re-organisation of the States in 1956, the Company was transferred to Mysore State (now Karnataka State) and became Hutti Gold Mines Limited. ${ }^{2,3}$

Mercury, being an active constituent of the Gold mining industry dates back to the $16^{\text {th }}$ century. Mercury is used in amalgamation and concentration of gold and thus is a major source of contamination in developing countries (Rojas et al 2001). ${ }^{4}$ The release of mercury in the biosphere is said to have exceeded 260,000 tons between the year 1550 and 1930, brought about due to gold mining procedures (Lacerda 1997) ${ }^{5}$. There was an exceptional hike in the gold prices experienced in the country in the 1970 s which further led to extensive gold mining for a very long period.

Arsenic also serves as an important constituent of gold mining. It has a low abundance in the earth's crust so it exists in the form of sulfide bearing minerals. The mining of gold and base metals is associated with sulfide mineralization thus ending up releasing arsenic in the environment. ${ }^{6}$

$\mathrm{Hg}$ and As are known toxicants that are hazardous to humans, wildlife and domestic animals and may accumulate in the environment causing serious damage to ecosystems and human health. Studies conducted throughout the world where gold mining occurs have reported the presence of high mercury and arsenic concentrations in human urine, breast milk, blood,hair, and nails, and in plant and fish samples.

High levels of $\mathrm{Hg}$ and As have been linked to detrimental effects on humans, such as skin problems, cancer, high blood pressure, cardiovascular diseases, and neurological and reproductive disorders among others. ${ }^{7}$ The potential harm of these toxicants to pregnant women, their fetuses and young children is an area of special concern. Women in these gold mining regions may engage in geophagy, or earth-eating, behaviors, which are common in artisanalmining areas due to poor nutritional status and cultural acceptance of this practice. ${ }^{7}$ 
More alarming is the fact that even low $\mathrm{Hg}$ exposure in mothers due to the contaminants released by gold mining could result in the fetus being exposed to high levels of $\mathrm{Hg}$ as it is concentrated by a factor of ten in the fetus relative to the mother. Thus, even a woman with a low level of mercury exposure could give birth to a child with significant birth defects. ${ }^{7}$ In addition, $\mathrm{Hg}$ exposure due to transmission through breast milk could have an effect on the healthy development of infants. ${ }^{8}$ Finally, infants and children are sometimes directly exposed to the mining processes themselves, since mothers often have their children at the mine site and processing areas while they are working and sometime young children even participate in mining as workers. ${ }^{9}$

Hence a questionnaire based survey was conducted amongst the local population of the Hatti village. The primary objective of this survey was to assess community risk knowledge and perception of potential Mercury and Arsenic toxicity and/or exposure from artisanal gold mining in the Hatti village locality.

\section{MATERIALS AND METHOD}

The study was conducted at the village of Hutti located in Raichur District in the Indian state of Karnataka. The estimated population of the area of Hutti Gold Mines, as of 2001 India census is 14,716 out of which $9 \%$ of the population is under six years of age. Males constitute $51 \%$ of the population and females $49 \%$. Hutti Gold Mines has an average literacy rate of $24 \%$. Most people in the village depend on water from rivers, natural wells, and wells constructed for human and livestock consumption and for mining.

Using a cross sectional design with a simple sampling technique, 100 people were recruited into the study and participated in the structured questionnaire survey. All of the individuals approached agreed to participate, (response rate was $100 \%$ ). These participants included the teachers and attenders of the Primary school of Hutti Village and also the general village people residing and working at the adjoining streets. Written informed consent was obtained from each participant. Since mining occurs in close proximity to housing and other economic activities, all people over the age of 18 were considered eligible to participate. The individuals who were recent immigrants of the place were excluded from the survey. A single researcher carried out the questionnaire survey, structured in English and provided to the participants. Those who needed it to be translated to the native language of Kannada, were assisted by the researchers.

The survey consisted of a total of 20 questions which included categorical questions ("Yes", "No", "Don't know") and openended questions. Questions pertaining to their quality of life and the source, quality of drinking water were included so as to identify the cause for the prevailing health issues. Participant's knowledge of the ill effects of gold mining was determined from basic questions regarding their awareness of associated health impacts. Questions were also directed at the effects on the general health of their children and prevalence of any dental abnormaltites observed with the sudden increase of gold mining in the region.

\section{RESULTS}

The age of the participants ranged from 18 years to 58 years; however, most were between 25 and 38 years of age. Of the hundred participants who participated in the survey, $39 \%$ lived in Hutti for more than ten years, and 34\% lived in the area for five to ten years, remaining $27 \%$ lived for less than five years. Hutti village was the main center for mining activities in Raichur. Amongst the study population, the proportion of participants who were aware of the gold mining were $81 \%$ and rest were unaware of the activity.

Most of the people who participated (67\%) in the survey were aware of the ill effects of mining. (Fig. 1) Around 30\% people said that the quality of drinking water has improved. Gold mining and its byproducts are known to cause lots of health issues. In growing age these signs and symptoms are more pronounced than elders. So the next question was to see the frequency of children taking leave from school due to health issues. $50 \%$ and $39 \%$ children took leave from school once a month and more than once a month respectively. (Fig. 2)

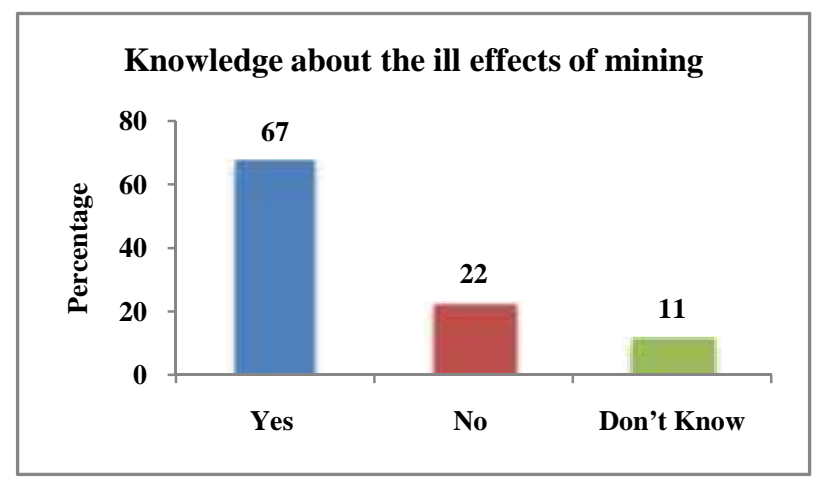

Fig 1

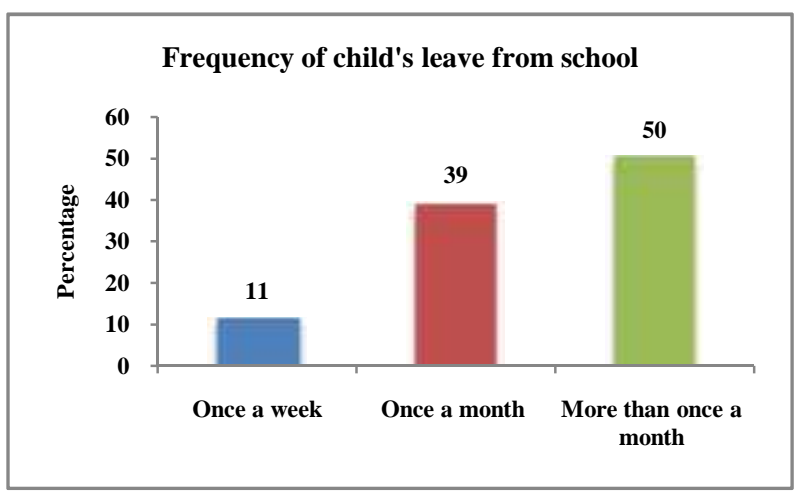

Fig 2

Some of the most common health problems noticed were dark brown pigmentation of the skin (47\%), (Fig. 5) loose stool $(38 \%)$, breathing difficulties $(49 \%)$ and fatigue $(47 \%)$. Around $11 \%$ people noticed loss of sensation of feet and hands especially towards the toes and fingers. When dental health was considered around 55\%people reported with white spot lesions on their tooth surface. (Fig. 3) When the female population was surveyed, around $3 \%$ reported abortions and miscarriages. (Fig. 4)

The poor accessibility and unavailability of health care centers was the main reason for the increased incidence of health issues. The majority of inhabitants of the village still choose to 
reside in the same area because of the lack of awareness about the ill effects of gold mining.

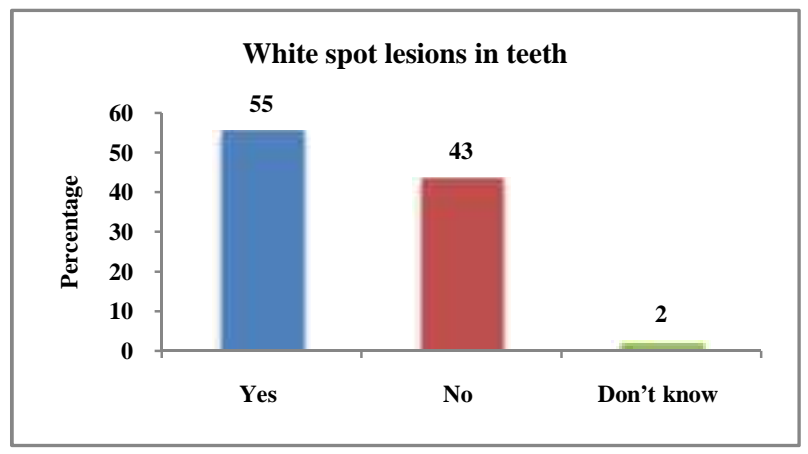

Fig 3

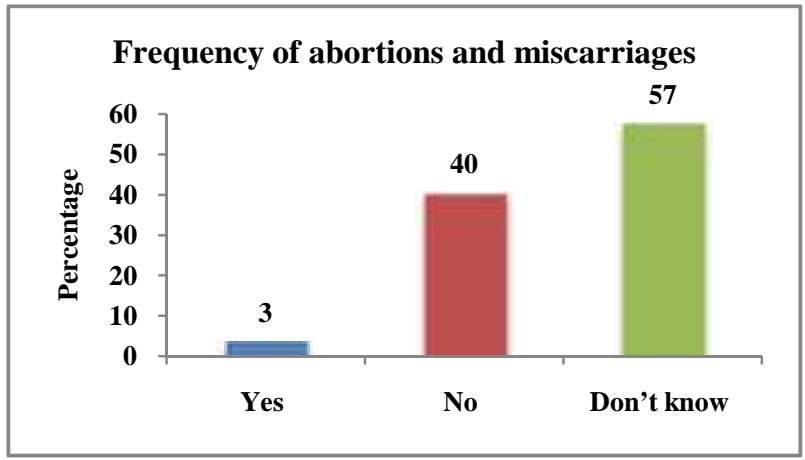

Fig 4

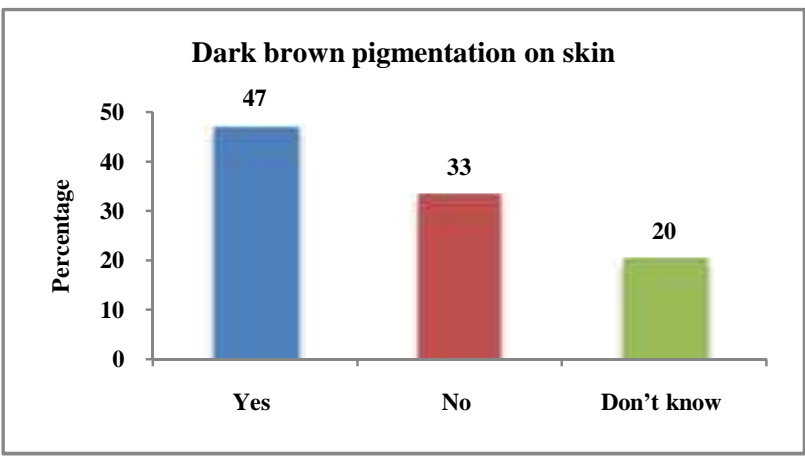

Fig 5

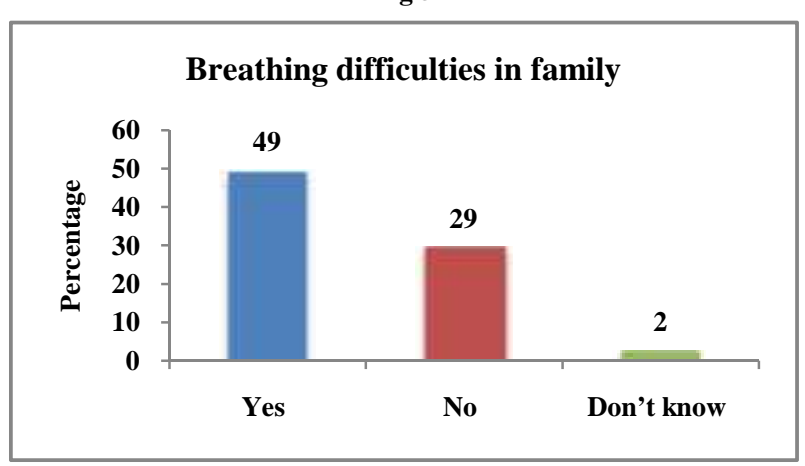

Fig 6

\section{DISCUSSION}

Traditional mining is increasingly common in many parts of the world with more than 30 million active miners in more than 55 countries. Mining activities are largely concentrated in rural areas that have very little infrastructure, and the individuals undertaking informal mining generally lack education, training, management skills and essential equipment for safe mining practices. Mercury $(\mathrm{Hg})$, used in the processing of gold ore, and arsenic (As), which is a constituent of some gold ores, are common occupational exposures that can result in widespread environmental contamination. $\mathrm{Hg}$ and $\mathrm{As}$ are known toxicants that are hazardous to humans, wildlife and domestic animals and may accumulate in the environment causing serious damage to ecosystems and human health. ${ }^{10}$

Chronic arsenic (As) and mercury $(\mathrm{Hg})$ exposure through ingestion can cause severe adverse effects on human health, especially via the consumption of contaminated groundwater. Epidemiological and experimental evidence ${ }^{11}$ is furthermore mounting that in utero or early life exposure to As and $\mathrm{Hg}$ may affect fetal development or increase rates of several malignant and non-malignant diseases.

In the present study area in a northeastern region of Karnataka (Hutti), India, factors impacting the natural secondary geochemical dispersion of Arsenic and mercury in groundwater and soil can depend upon factors such as topography, water table depth, drainage, soil type, and underlying geology. This area also has several historic gold mines with some presently active and many abandoned.,

In the current study 100 inhabitants of the village participated in the questionnaire survey of which majority were in the age group of 25-38 years. It was observed that $81 \%$ of the participants were aware of the gold mining in Hutti.

The most common ill effects of arsenic and mercury poisoning could be skin problems, malignancies, cardiovascular diseases, gastro intestinal problems, neurological and reproductive disorders as seen in other similar studies across the world. Similar defects were seen in our present study amongst the local population which were in accordance with the global trend of mining related health disorders. ${ }^{12}$ Although more toxic mercury species (e.g., dimethylmercury) are present in trace levels in seafood, the primary risk of toxicity arises from $\mathrm{MeHg}$. MeHg is the predominant form of mercury in seafood, is readily absorbed from the digestive tract, and can rapidly cross the blood-brain barrier to exert its neurological effects. Long-lived and predatory fish (e.g., sharks) absorb $\mathrm{MeHg}$ from their diets, leading to higher $\mathrm{MeHg}$ levels than those present in species lower on the food chain. ${ }^{12,13}$

Inorganic arsenic is highly toxic: high levels can cause neurological damage, anemia, leucopenia, and vascular disease, while low-level chronic exposure increases an individual's risk of developing cancer. MMA and DMA were previously believed to be non-toxic, but have recently been linked to arsenic-induced toxicity. ${ }^{1,5}$ Humans can metabolize inorganic arsenic to MMA and DMA, and it is believed that these metabolites contribute significantly to carcinogenicity and overall toxicity, particularly in their trivalent forms. Arsenic toxicity due to gold mining is notable, but the metal is present in the form of non-toxic arsenobetaine and arsenosugars.

The major heavy metal risk posed by gold mining is exposure of a developing fetus to $\mathrm{MeHg}$. Even low $\mathrm{Hg}$ exposure in mothers due to the contaminants released by gold mining could result in the fetus being exposed to high levels of $\mathrm{Hg}$ as it is concentrated by a factor of ten in the fetus relative to the mother. ${ }^{72}$ Thus, even a woman with a low level of mercury exposure could give birth to a child with significant birth 
defects. In addition, $\mathrm{Hg}$ exposure due to transmission through breast milk could have an effect on the healthy development of infants.

This is in accordance with the results of our survey which reported an abortion and miscarriage rate of 3\%. Also, the percentage of children taking leave from school due to health problems were between $40 \%-50 \%$.

Another hurdle which contributed in worsening gold mining related health problems was absence of a proper primary health care or referral centre. Thus, there was lack of awareness as well as failure to intervene the disease in the early phase amongst the population.

While groundwater contamination is hypothesized to be the main route of As and $\mathrm{Hg}$ exposure, there could also be presence of highly elevated As and $\mathrm{Hg}$ levels in soil samples in the area. Investigation of other possible significant routes of exposure as well as their relative contributions to toxicity should be studied. ${ }^{8}$ The historic gold mine workings of the Hutti Gold Mining company may be a significant contributor to localized pollution in Hutti and other neighbouring regions.

\section{CONCLUSION}

Additional studies to determine, temporal variation, the nature of As and Hgmobilization, particularly whether previous and ongoing mining activities are playing a role, are crucial in guiding efforts to identify at-risk communities and remedy the effects of this contamination. If historic gold mining has played a role in contamination, increasing interest in there opening of previously closed mines and the prospecting of new regions in the and around Karnataka should be conducted along with sound monitoring and assessment of the environment and the health effects resulting from its degradation. As various surveys have identified many additional communities with elevated groundwater arsenic and mercury, environmental contamination appears to be more widespread than the present study area. Both medical screening and regular water quality analysis programs should be continued or organized in the region immediately. ${ }^{8}$

\section{References}

1. Naganna C. Gold mineralization in the Hutti mining area, Karnataka, India. Economic Geology. 1987 Dec 1; 82(8):2008-16.

2. Curtis LC, Radhakrishna BP. Hutti-Gold Mine into 21st Century. GSI Publications. 1995 May 7; 3(1).

3. Sarma DS, Mcnaughton NJ, Fletcher IR, Groves DI, Mohan MR, Balaram V. Timing of gold mineralization in the Hutti gold deposit, Dharwar Craton, South India. Economic Geology. 2008 Dec 1; 103(8):1715-27.
4. Drake PL, Rojas M, Reh CM, Mueller CA, Jenkins FM. Occupational exposure to airborne mercury during gold mining operations near El Callao, Venezuela. International archives of occupational and environmental health. 2001 Apr 1; 74(3):206-12.

5. Van Straaten P. Mercury contamination associated with small-scale gold mining in Tanzania and Zimbabwe. Science of the Total Environment. 2000 Oct 2; 259(1):105-13.

6. Wickre JB, Folt CL, Sturup S, Karagas MR. Environmental exposure and fingernail analysis of arsenic and mercury in children and adults in a Nicaraguan gold mining community. Archives of Environmental Health: An International Journal. 2004 Aug 1; 59(8):400-9.

7. Charles E, Thomas DS, Dewey D, Davey M, Ngallaba SE, Konje E. A cross-sectional survey on knowledge and perceptions of health risks associated with arsenic and mercury contamination from artisanal gold mining in Tanzania. BMC public health. 2013 Jan 25; 13(1):74.

8. Skerfving S. Mercury in women exposed to methylmercury through fish consumption, and in their newborn babies and breast milk. Bulletin of environmental contamination and toxicology. 1988 Oct $1 ; 41(4): 475-82$.

9. Chakraborti D, Rahman MM, Murrill M, Das R, Patil SG, Sarkar A, Dadapeer HJ, Yendigeri S, Ahmed R, Das KK. Environmental arsenic contamination and its health effects in a historic gold mining area of the Mangalur greenstone belt of Northeastern Karnataka, India. Journal of hazardous materials. 2013 Nov 15; 262:1048-55.

10. Kolb J, Rogers A, Meyer FM. Relative timing of deformation and two-stage gold mineralization at the Hutti Mine, Dharwar Craton, India. Mineralium Deposita. 2005 Mar 1; 40(2):156-74.

11. Hoedoafia MA, Cheabu BS, Korang V. The effects of small scale gold mining on living conditions: A case study of the west gonja district of Ghana. International Journal of Social Science Research. 2014 Mar 11; 2(1):151-64.

12. Bose-O'Reilly S, Lettmeier B, Gothe RM, Beinhoff C, Siebert U, Drasch G. Mercury as a serious health hazard for children in gold mining areas. Environmental research. 2008 May 31; 107(1):89-97.

13. Grandjean P, White RF, Nielsen A, Cleary D, de Oliveira Santos EC. Methylmercury neurotoxicity in Amazonian children downstream from gold mining. Environmental health perspectives. $1999 \mathrm{Jul} ; 107$ (7): 587.

14. Smedley PL, Edmunds WM, Pelig-Ba KB. Mobility of arsenic in groundwater in the Obuasi gold-mining area of Ghana: some implications for human health. Geological Society, London, Special Publications. 1996 Jan $1 ; 113(1): 163-81$.

\section{How to cite this article:}

Amitha Hegde et al.2017, Effects of Gold Mining on The General Population. Int J Recent Sci Res. 8(3), pp. 16266-16269. DOI: http://dx.doi.org/10.24327/ijrsr.2017.0803.0115 